\title{
AS POTENCIALIDADES LÚDICAS DA EDUCAÇÃO ESTATÍSTICA NOS ANOS INICIAIS
}

\author{
THE LUDIC POTENTIALITIES OF STATISTICAL EDUCATION IN THE EARLY YEARS
}

\author{
THAYS RODRIGUES VOTTO 1 \\ MAUREN PORCIÚNCULA MOREIRA DA SILVA²
}

\section{RESUMO}

0 presente artigo objetiva compreender como professores dos Anos Iniciais do Ensino Fundamental concebem a ludicidade, além de identificar o potencial lúdico nas estratégias pedagógicas estatísticas contempladas na sua prática docente. 0 percurso metodológico foi pautado pela abordagem qualitativa, valendo-se de entrevistas semiestruturadas realizadas com sete professores. Estas foram submetidas à Análise de Conteúdo. Durante as análises emergiram duas categorias temáticas, a saber: As compreensões de professores dos Anos Iniciais acerca da ludicidade e Vivências lúdicas nas atividades estatísticas. Os resultados e discussões descortinaram que as compreensões docentes acerca do lúdico distribuem-se em dois polos: stricto sensu, relacionado à materialidade do lúdico e latu sensu, compreendendo 0 lúdico como um fenômeno interno do sujeito. Outrossim, 0 estudo apreendeu que atividades que tornam 0 aluno ativo no seu processo de aprendizagem, a partir de construção de gráficos ou realização de pesquisas de forma coletiva, podem proporcionar vivências lúdicas aos alunos.

Palavras-chave: Estatística. Ludicidade. Anos Iniciais.

\section{ABSTRACT}

This article aims to understand how teachers from the Early Years of Elementary Education conceive ludicity in addition to identifying the ludic potential in statistics pedagogical strategies contemplated in their teaching practice. The methodological route was guided by the qualitative approach using semi-structured interviews conducted with seven teachers. These were submitted to Content Analysis. During the analysis, two thematic categories emerged, to know: The teachers' understandings of the Early Years about ludicity and Ludic experiences in statistical activities. The results and discussions reveal that the teachers' understandings about ludic are highlighted in two areas: stricto sensu, related to the materiality of ludic and latu sensu, understanding ludicity as an internal phenomenon of the subject. In addition the study apprehended that activities that make the student active in their learning process from the graphics building or conducting research collectively, can provide ludic experiences to students.

Keywords: Statistic. Ludicity. Early Years.

\footnotetext{
1 Mestre em Educação em Ciências - FURG. Doutoranda em Educação em Ciências. Universidade Federal do Rio Grande - FURG. E-mail: thayvotto@ hotmail.com. Orcid: 0000-0002-7595-5165.

2 Doutorada em Informática na Educação - UFGRS. Universidade Federal do Rio Grande - FURG. E-mail: mauren.porciuncula@gmail.com. Orcid: 0000-0003-1161-8220
} 


\section{APONTAMENTOS INICIAIS}

A partir de uma demanda da sociedade por desenvolver nos cidadãos habilidades referentes à leitura e interpretação de informações disseminadas pela mídia, a fim de que um sujeito possa compreender a realidade em que vive, a Estatística foi inserida no currículo para os Anos Iniciais (BRASIL, 1997). Quando consideramos a Estatística como uma das ciências metodológicas fundamentais, sendo a base de método científico experimental (BATANER0, 2001), justifica-se à inserção de habilidades e competências estatísticas no currículo escolar internacional e brasileiro (BRASIL, 1997, 2018; FRANKLIN et al., 2007).

A Educação Estatística está centrada no "estudo da compreensão de como as pessoas aprendem Estatística envolvendo os aspectos cognitivos e afetivos e 0 desenvolvimento de abordagens didáticas e de materiais de ensino" (CAZORLA et al., 2017, p. 13), valendo-se de contribuições de diferentes áreas do conhecimento, como Educação Matemática, Psicologia, Pedagogia, Filosofia, Matemática, além da própria Estatística. Nesse contexto, o presente artigo apresenta e discute a contribuição tanto da Pedagogia quanto da Psicologia, para compreender o conceito de ludicidade e como ela pode potencializar a aprendizagem estatística nos Anos Iniciais.

Os currículos que incluem a Estatística podem contribuir para que os estudantes desenvolvam os requisitos para serem considerados letrados em Estatística, tais como: saber por que os dados são necessários e como podem ser produzidos; ter familiaridade com termos e ideias básicas relacionadas à estatística descritiva e exibições gráficas e tabulares; compreender as noções básicas de probabilidade e saber como as conclusões ou inferências estatísticas são alcançadas (GAL, 2002). A construção deste conhecimento, de forma reflexiva, pode contribuir para o exercício da cidadania, por viabilizar a interpretação de informações, nos âmbitos escolar, profissional ou pessoal (GAL, 2002).

Os documentos oficiais que orientam a Educação brasileira elucidam o ensino da Estatística por meio da construção e interpretação de gráficos e tabelas, coleta de dados e realização de pesquisas (BRASIL, 1997; 2018). Entretanto, algumas pesquisas referem que a Estatística, na Educação Infantil e nos Anos Iniciais, prioriza a interpretação de tabelas e gráficos em detrimento da construção destes (GUIMARÃES et al., 2009). Outrossim, tem sido proposta a aprendizagem dessas representações em si mesmas e não a sua função, excluindo, dessa forma, a inferência, ou seja, a partir de reproduções ou interpretações mecânicas (BORBA et al., 2011; VOTTO, SCHEREIBER \& PORCIÚNCULA, 2017; VOTTO, 2018).

Um Estado da Arte realizado por Guimarães et al. (2009) evidenciou uma lacuna em relação à apresentação dos conceitos e das análises de proposições didáticas que poderiam subsidiar a atuação docente em relação ao ensino da Estatística desde os Anos Iniciais. Outrossim, de acordo com as autoras, a ausência de divulgação de pesquisas se dá tanto no âmbito da academia, quanto no de socialização de práticas realizadas por professores desses níveis de ensino.

0 Pacto Nacional pela Alfabetização na Idade Certa - PNAIC preconiza que tanto a Estatística como a Probabilidade e a Combinatória, podem ser inseridas como conteúdos ainda no ciclo de alfabetização. Contudo, não de maneira formalizada, mas que podem ser iniciadas a partir de situações lúdicas (BRASIL, 2014). Dessa forma, compreendemos que por meio da ludicidade, a Estatística pode ser inserida nesse nível de ensino de forma prazerosa e agradável, ao conceber 0 aluno como um sujeito dotado de afetos e motivações que precisam ser considerados no processo educativo.

Face ao exposto, o presente artigo tem como objetivos, num primeiro momento, compreender como professores dos Anos Iniciais do Ensino Fundamental concebem a ludicidade, e posteriormente identificar o potencial lúdico nas estratégias pedagógicas estatísticas contempladas na sua prática docente. Nessa direção, destacamos que no discurso docente, obtido por meio de entrevistas, os 
participantes da pesquisa narram atividades estatísticas já realizadas com suas turmas, analisando junto com a pesquisadora o potencial lúdico destas estratégias.

Ademais, sistematizamos duas destas estratégias que, de acordo com os professores, têm potencial lúdico. Estas salientam a coleta de dados e construção coletiva de um gráfico valendo-se de materiais concretos, outrossim uma atividade de pesquisa. A fim de socializar com o leitor o nosso entendimento acerca da conceitualização do lúdico, a próxima seção disserta sobre a teoria da ludicidade adotada nesse artigo.

\section{A LUDICIDADE COMO UM FENÔMENO INTERNO}

A ludicidade, os jogos, brinquedos e brincadeiras foram amplamente investigados a partir de diferentes perspectivas, como a sociocultural, nesta destaca-se as teorias de Huizinga (1971), Kishimoto (1998; 2006) e Brougère (1998; 2006). Tais autores enfatizam o jogo e o brinquedo como elementos desenvolvidos a partir do contexto sociocultural do sujeito, por meio do qual ele estabelece um diálogo simbólico com o seu povo, originando uma cultura lúdica (BROUGÈRE, 2006).

No contexto educativo, apresentamos a relevância dos escritos de Kishimoto, que versam sobre o surgimento do jogo educativo, instigando o educador a refletir sobre as funções do jogo: lúdica e pedagógica. Acarretando no desafio docente de equilibrar tais funções, com intuito de valorizar elementos como a liberdade, espontaneidade, prazer e alegria, próprios dos jogos, com a intencionalidade para um determinado fim, oriunda da prática pedagógica (KISHIMOTO, 1998).

Almeida (1987) disserta sobre uma Educação Lúdica, esta consiste em um modelo educacional em que a ludicidade direciona as decisões e ações de caráter pedagógico. De acordo com 0 referido autor, está distante da concepção ingênua de passatempo ou diversão superficial. Ela é uma ação inerente a todos os seres humanos, desde a criança até 0 adulto e aparece sempre como uma forma transacional em direção a algum conhecimento (ALMEIDA, 1987). A premissa exaltada exige do estudante uma ação ativa, indagadora, reflexiva, além de criativa e socializadora. Essas relações constituem a essência da psicogenética da educação lúdica (ALMEIDA, 1987). Dessa forma, opõe-se à passividade, submissão e alienação referentes à pedagogia dominadora impostas pela Educação Bancária de Freire (1981; 2002).

Face ao exposto, compreendemos que as teorias acerca da ludicidade citadas acima nos ajudam a compreender parte desse complexo fenômeno, mas é imprescindível refletirmos sobre 0 significado do lúdico adotado nesta pesquisa, a partir da dimensão interna do sujeito, conceito adotado neste estudo. Nesse sentido, de acordo com Chateau (1987) atividade lúdica se separa do objeto, este configura-se apenas como um instrumento para alcançar certo resultado que está relacionado com o sujeito, com uma reflexão sobre si mesmo. Por exemplo, uma criança que fez um castelo com cubos, para ela não interessa o material em si (cubos), mas sim o sentimento de realização de sua obra.

Na mesma ótica, Luckesi (1998, p. 27) concebe que "a ludicidade é a experiência de plenitude que ela possibilita a quem a vivencia em seus atos". 0 referido autor conceitua a atividade lúdica como aquela que possibilita uma plenitude da experiência, proporcionando vivências de prazer, alegria e bem-estar ao sujeito. Sendo assim, o lúdico está presente em muitos momentos de nossa vida, e nem todos são necessariamente divertidos, como estar em uma boa roda de conversa, escrever um texto, dançar, entre outros exemplos (LUCKESI, 1998; 2000).

Indo ao encontro do que aludiu Luckesi (1998), Brougère (1998) preconiza que a atividade lúdica pode ser analisada por meio de um reconhecimento objetivo, a partir da observação externa, 
entretanto configura-se como um sentimento pessoal que cada indivíduo pode ter em certas circunstâncias. Sendo assim, a ludicidade pode ser concebida como um fenômeno interno do sujeito que possui manifestações no exterior (LUCKESI, 2000). Face ao exposto, não se pode falar que uma atividade é lúdica em si mesma, mas sim que ela é potencialmente lúdica, pois o lúdico diz respeito a como 0 sujeito vivencia determinada ação. Superando a visão materialista de ludicidade atrelada somente aos jogos e brincadeiras e, por conseguinte, restrita ao universo infantil.

Com 0 intuito de compreender de que forma os professores concebem a ludicidade, e ainda se suas práticas pedagógicas para o ensino e aprendizagem de Estatística são potencialmente lúdicas, a próxima sessão descreve a metodologia do presente estudo e, na sequência, os resultados e discussões deste artigo.

\section{CAMINHOS METODOLÓGICOS}

0 presente artigo é um recorte da dissertação de mestrado da primeira autora sob orientação da segunda, apresentando os seguintes compreender como professores dos Anos Iniciais do Ensino Fundamental concebem a ludicidade, e a partir dessa compreensão, identificar o potencial lúdico nas estratégias pedagógicas estatísticas contempladas na sua prática docente.

Quanto à sua natureza, este estudo apresenta cunho qualitativo, no qual participaram os sete professores que assumiram desenvolver um maior número de habilidades estatísticas, verificadas por meio de um Checklist Estatístico ${ }^{3}$. 0 delineamento metodológico se deu por meio de entrevista semi-estruturada. Este tipo de entrevista, de acordo com Minayo (2008), possibilita ao entrevistado discorrer sobre determinado assunto sem se prender à indagação formulada.

A entrevista compreendeu três momentos. Primeiramente englobou questionamentos referentes a como os professores concebiam a ludicidade, na sequência uma breve conversa sobre o conceito de ludicidade adotado nesta pesquisa, pautado em Chateau, Luckesi e Brougère. Por fim, os participantes do estudo foram questionados sobre as estratégias pedagógicas desenvolvidas nas aulas de Estatística, se estas poderiam proporcionar vivências lúdicas aos alunos.

No que tange à metodologia de análise dos dados coletados na fase qualitativa, valeu-se da Análise de Conteúdo proposta por Bardin (2011). Considerando as grandes etapas da metodologia: I) organização da análise, II) codificação, III) categorização, IV) inferência e V) tratamento informático. 0 corpus de análise do presente artigo englobou a transcrição das entrevistas com os 7 professores. Após uma leitura flutuante do corpus, foram constituídas as unidades de registro (recorte do discurso dos professores), as quais são explicitadas em diversos momentos ao longo do artigo (etapas I e II).

A referida metodologia prevê a categorização das unidades de registro, esta foi realizada a posteriori, ou seja, emergiram dos conteúdos e dos sentidos presentes nas entrevistas com os professores (etapa III). Emergiram das análises da dissertação de mestrado da primeira autora, duas categorias gerais, a saber: Estratégias para o ensino de Estatística nos Anos Iniciais, publicada em um capítulo do livro "Perspectivas para o ensino e aprendizagem de Estatística e Probabilidade" (VOTTO \& PORCIÚNCULA, 2019) e A Educação Estatística nos Anos Iniciais e suas Potencialidades Lúdicas, dissertada e discutida neste artigo. Esta última foi subcategorizada em dois eixos: As compreensões de professores dos Anos Iniciais acerca da ludicidade e Vivências lúdicas nas atividades estatísticas.

30 referido Checklist contemplou todas as habilidades estatísticas previstas nos PCN e na BNCC (BRASIL, 1997; 2018), este foi utilizado em uma etapa quantitativa na pesquisa de mestrado da primeira autora (VOTTO, 2018), que serviu como rastreamento para a etapa qualitativa descrita neste artigo. 
As últimas etapas da Análise de Conteúdo (BARDIN, 2011) - inferência e tratamento informático possibilitaram o confrontamento e interpretação dos discursos docentes com as teorias acerca da ludicidade, bem como 0 tratamento informático apresentando de modo quantitativo alguns aspectos evidenciados nos discursos docentes. Neste, fizemos uso de uma nuvem de palavras com o software Wordclouds (https://www.wordclouds.com/, 2018), enfatiza-se que quanto maior 0 tamanho das palavras na nuvem, maior será a sua frequência no discurso docente (o texto submetido ao software são as entrevistas transcritas na íntegra). A referida nuvem de palavras é apresentada a seguir na sessão dos resultados deste artigo.

\section{RESULTADOS E DISCUSSÕES}

Com 0 intuito de introduzir ao leitor as temáticas emergentes dos discursos docentes, acerca das potencialidades lúdicas para o ensino e aprendizagem de Estatística nos Anos Iniciais, apresentamos a seguir uma nuvem de palavras.

Figura 1 - Representação das palavras oriundas dos discursos docentes.

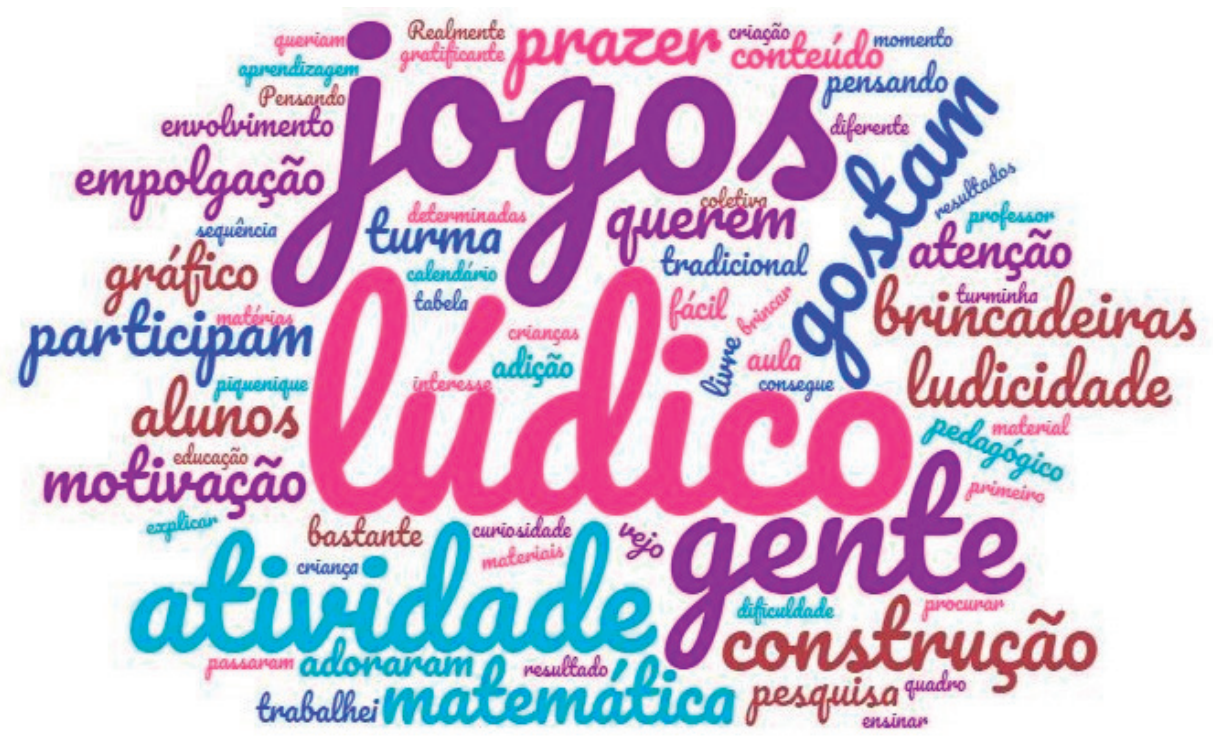

Fonte: Produzido pela autora.

A partir da observação da Figura 1, compreendemos que o lúdico se apresenta no discurso docente primeiramente atrelado aos jogos e às atividades, e secundariamente a aspectos subjetivos como motivação, empolgação e prazer. Este resultado evidencia certa materialidade do pensamento do professor em relação à ludicidade. Na sequência apresentamos a subcategorização dos discursos docentes, por meio da análise de conteúdo: As compreensões de professores dos Anos Iniciais acerca da ludicidade e As vivências lúdicas nas atividades estatísticas. Cada uma dessas subcategorias deu origem a uma subseção, as quais serão analisadas a seguir. 


\section{AS COMPREENSÕES DE PROFESSORES DOS ANOS INICIAIS ACERCA DA LUDICIDADE}

A entrevista com os docentes abrangeu questões referentes à conceituação que os participantes da pesquisa atribuíam, no momento, à ludicidade e ao lúdico. Sendo assim, a presente subcategoria temática pretende analisar a partir de quais enfoques os professores realizaram tal conceituação. 0 primeiro enfoque evidenciado por alguns professores ao conceituar ludicidade é relacioná-la com a utilização de jogos e brincadeiras, como discorrem os excertos abaixo:

P4: eu acho que depende muito da idade, que tem crianças que são mais infantis, a brincadeira tem que ser outro tipo de brincadeira, porque eles já estão amadurecendo, mas eles ainda brincam, eles gostam.

P6: a matemática eu gosto muito de trabalhar com jogos, uso jogos de sequência lógica, material dourado, banco imobiliário, jogo da vida, são jogos que trazem a educação matemática disfarçado de uma brincadeira de um jogo, e eles gostam muito.

(Entrevista com os professores, 2017)

Podemos relacionar esse vínculo entre a ludicidade e os jogos e brincadeiras a uma visão stricto sensu do lúdico, talvez devido à crença de uma materialidade da ludicidade por meio desses objetos. Dessa forma, o lúdico fica restrito ao universo infantil. Algumas pesquisas abordam a ludicidade principalmente por meio de jogos e brincadeiras, corroborando com essa crença (LAPA, 2017; LUGLE, 2006; MASCARIN, 2017; PIN, 2016; VALIO, 2014).

Indo ao encontro da concepção elencada acima, o professor 6 realça que "a brincadeira tem que estar sempre presente na sala de aula, porque, às vezes, a gente acha que dentro da escola acabou a brincadeira, que a brincadeira é só na hora do recreio." (P6). 0 referido professor explana ainda que 0 ambiente da escola tende a reprimir a ludicidade em muitos aspectos "A ludicidade ela está no dia a dia, e quando a gente chega na escola parece que aquilo é cortado e fica fora, e aqui é outra coisa, que não é legal, que não é prazeroso." (P6).

Atrelar 0 lúdico ao prazer, como enfatiza o professor 6, é uma prática comumente realizada, como descortina a revisão realizada por Sartori e Duarte (2017), ao elucidar que o lúdico como sinônimo de algo prazeroso, emerge com certa frequência nos trabalhos publicados nos anais do XI Encontro Nacional de Educação Matemática. Imbricado nessa concepção temos 0 enunciado que expõe a importância de se aprender brincando, como dissertar-se-á a seguir.

Nessa direção, o discurso abaixo salienta o quanto o trabalho com o lúdico, a partir do enunciado aprender brincando, pode tornar a aprendizagem mais fácil para os educandos "o lúdico é eles trabalharem brincando uma coisa que chame a atenção deles, que eles aprendam sem se dar conta, [...] é a facilidade com que eles aprendem [...] Eles [alunos] dizem "Tia a gente não fez nada hoje, a gente só brincou" (P1).

A partir do exposto até aqui, percebe-se que a importância atribuída à ludicidade, principalmente aos jogos e brincadeiras no ambiente educacional, dar-se-á pela característica desses elementos possibilitarem que os alunos aprendam conteúdos compreendidos como "sérios", de forma prazerosa, "sem se dar conta". A esse respeito, Sartori (2015) salienta, a partir de seu estudo, que as justificativas atribuídas pelos professores para a utilização do lúdico nas aulas de matemática são, dentre outras: ter o desejo de aprender matemática e de que a criança precisa aprender com prazer. 
Interligada a estas duas, aparece a importância da satisfação do aluno em aprender brincando. Ressaltamos ainda Araújo (2000), que em sua pesquisa correlaciona a ludicidade ao prazer e diversão, enfatizando a importância de vivenciar a matemática e desenvolver a aprendizagem brincando.

Nesse sentido, não é incomum abordar a ludicidade a partir de um enfoque dito materialista, concebendo as "atividades lúdicas" como ferramentas facilitadoras do processo de ensino e aprendizagem. Compreendemos, a partir dos discursos categorizados acima, que a ludicidade é frequentemente relacionada aos jogos e brincadeiras. Podemos compreender os jogos tendo em vista duas funções distintas, mas que podem relacionar-se, segundo alguns autores como Kishimoto (1998), a função lúdica e a função pedagógica. Os excertos abaixo apresentam algumas dessas compreensões,

P2 [realizou seu TCC sobre a ludicidade]: eu acredito muito na ludicidade, abordei 2 focos: lúdico livre e o lúdico pedagógico. 0 lúdico livre tu deixa por conta deles, eles optam por aquilo que eles acharem mais interessante. E o pedagógico é quando tu inclui um conteúdo, alguma temática. [...] 0 lúdico livre estava mais presente nas aulas de artes e educação física (P2).

P4: [a ludicidade é] fazer a atividade relacionada com o que tu está dando na aula.

(Entrevista com os professores, 2017)

Os excertos acima denotam que as brincadeiras podem ser adaptadas de acordo com o conteúdo e tema que está sendo desenvolvido na sala de aula. Diante do exposto nesses últimos excertos, percebemos que, assim como Kishimoto (1998), o jogo pode apresentar duas funções, uma lúdica, que diz respeito à própria ação de jogar, livremente, sem objetivos rígidos, e uma função pedagógica, na qual estabelecemos metas e objetivos de aprendizagem para determinada atividade ou jogo. Entretanto, é relevante frisarmos que o professor que tem o interesse em desenvolver a sua prática pedagógica envolvendo a ludicidade por meio de jogos, deve tentar fazer com que essas duas funções operem sinergicamente, senão corre-se o risco de uma função se sobressair em relação à outra.

No que diz respeito à relação da ludicidade com o movimento corporal, como explicitado pela fala da professora ao mencionar que o lúdico livre estaria presente nas aulas de Educação Física, valemo-nos de Brougère (1998), o autor infere que essa concepção também é presente antes da Revolução Francesa, compreendendo-a como uma das características do jogo, na qual há uma oportunidade de exercitar o corpo na escola, ou ainda com a função de relaxamento após longo período de esforço mental durante as aulas.

Ainda, emergiu dos discursos de alguns entrevistados o lúdico como uma forma de introdução aos conteúdos, de forma agradável que - podendo ou não ter a presença de jogos e brincadeiras predispõe o ensino do conteúdo formal.

P4: acho que é aí que entra o lúdico, na verdade ele vem primeiro, a partir dele introduzir o conteúdo.

P6: eu gosto de mostrar pra eles no jogo a conta, mas que também existe essa conta mais formal, gosto muito de fazer essa relação. [...] acho que quando a gente parte do lúdico torna tudo mais fácil.

(Entrevista com os professores, 2017) 
Partindo dos excertos manifestos acima, recorremos a Dantas (2002) ao enfatizar que uma possibilidade para a inserção de aspectos lúdicos na prática educativa, seria respeitar a concepção de que a atividade lúdica (livre) tende ao jogo (intencional). Isto é, os educadores deveriam incorporar cada atividade nova (ou conteúdo) através de uma etapa lúdica, destacando a importância de que os alunos interajam com o objeto de forma espontânea, sem objetivos pré-determinados, precedendo a formalização das noções e conteúdos acerca desse objeto.

Alguns dos professores investigados compreendem que a ludicidade pode estar relacionada com uma questão de atitude docente, indo ao encontro do que preconizou Luckesi (2000; 2005). Destacamos um trecho do discurso da professora 3, que denota que "a ludicidade não é só brincadeiras, dinâmicas, mas é também de estar ali proporcionando algo que é prazeroso pra eles [...] Até mesmo uma atividade que não é uma brincadeira, a forma como tu coloca se torna tão lúdica." (P3). A professora exemplifica ao conceber a ludicidade também como uma atitude do professor ao realizar/conduzir determinada atividade, que a postura do professor em sala de aula pode proporcionar vivências lúdicas aos alunos. Para tanto, o professor vale-se da entonação da voz, o envolvimento deste com a atividade, da forma com que estabelece um diálogo com a turma, da forma como 0 professor valoriza a subjetividade discente.

Nessa direção, concebemos a situação mencionada acima como uma atitude lúdica do professor em relação aos seus alunos, esta é um aspecto fundamental para que possamos alcançar uma educação potencialmente lúdica. 0 professor precisa valer-se de uma atitude lúdica, dentre outros aspectos, como a escolha de materiais, metodologias ativas, informações contextualizadas e que vão ao encontro dos interesses e motivações discentes.

Conceituamos atitude lúdica do professor aquela que dá ênfase no processo de planejamento e organização da aula, aos interesses dos alunos, envolvendo-os nas atividades, dando voz a eles, acolhendo suas sugestões, dúvidas e anseios em relação ao processo ensino e aprendizagem, que percebe 0 aluno como um sujeito que, por sua vez, é dotado de afetos, motivações e interesses próprios e que precisam ser enaltecidos durante o processo educativo formal. Compreendendo, assim como Luckesi (2005), Brougère (1998), que a ludicidade está associada a fatores subjetivos do sujeito. Dessa forma, é possível compreender a ludicidade no seu sentido latu sensu.

Apreendemos ainda durante a análise do corpus que compõe essa pesquisa, que conceito de ludicidade presente no discurso de alguns professores emerge como uma estratégia de ensino que se coloca em disparidade ao ensino tradicional.

P6: o currículo não tem que ser fechado nas matérias que são determinadas, o professor tem autonomia pra isso [...] e os professores que seguem à risca fazem porque querem seguir uma linha mais tradicional, mas tem outras formas.

P7: eu vejo o lúdico com uma forma de tu ensinar alguma coisa sem ter que fazer a cobrança, e sem ser de uma forma tradicional.

(Entrevista com os professores, 2017)

Face ao exposto pelos educadores, percebemos que a ludicidade pode ser uma forma de conceber a educação, que rompe com os parâmetros tradicionais educativos, principalmente àqueles métodos de ensino preconizados pela tendência pedagógica Liberal Tradicional. Esta, de acordo com Libâneo (1985), baseia-se na exposição do conteúdo pelo professor, que assume uma postura de 
autoridade e detentor do conhecimento. Este último, concebido como verdade absoluta e com caráter enciclopédico, deve ser absorvido pelos alunos, por meio de exercícios mecânicos de memorização e posterior reprodução em prova, para disciplinar a mente e formar hábitos (LUCKESI, 1994). Se na tendência tradicional se preconizava a disciplina como meio de garantir a atenção e o silêncio (LUCKESI, 1994), na educação lúdica prevê-se o contrário, ou seja, um aluno ativo que constrói seu próprio conhecimento em interação com o meio e com o outro, dotado de interesses, motivações e afetos que são considerados no processo educativo.

Historicamente é atribuído à atividade, jogo ou material concreto (objeto) a característica de "lúdico". Entretanto, as discussões que estamos desenvolvendo aqui pretendem ampliar esse conceito, não mais relacionando à ludicidade um atributo material presente nesta ou naquela atividade/jogo. Mas, concebendo-a, a partir dos pressupostos teóricos adotados (BROUGĖRE, 1998; CHATEAU, 1987; LUCKESI, 2002), como um fenômeno interno do sujeito, que engloba os sentimentos de prazer, alegria, bem-estar, e que nem sempre são extremamente divertidos.

Por exemplo, uma vassoura, para muitos é concebida como um instrumento de limpeza, para uma determina criança, ela pode tornar-se um cavalo, quando ela se vale desse instrumento como suporte para sua brincadeira e imaginação, Ihe proporcionando prazer, alegria e bem estar. Assim, é a vassoura que é lúdica? Ou a ação empreendida pela criança e o sentimento que a interação desta com 0 objeto que lhe proporciona? A partir dessa reflexão, apreende-se que a ludicidade é algo que ocorre de dentro para fora, sendo o sujeito e sua vivência que irão determinar se algo é lúdico ou não.

Essa compreensão é pouco evidenciada nas pesquisas a nível de pós-graduação que investigam a Educação Matemática e ausente nas que abordam a Educação Estatística (VOTTO, 2018), com exceção a pesquisa de mestrado da primeira autora, cujo recorte é apresentado neste artigo. Por isso, neste estudo evidenciamos quais as estratégias pedagógicas para 0 ensino e aprendizagem estatística demonstram potencial lúdico. Embora saibamos, que não é possível generalizar tais evidências, pois o que vivenciado como lúdico por um aluno pode não o ser por outro, reside aí a importância do professor conhecer 0 seu aluno.

Na próxima subseção são enfatizadas as estratégias pedagógicas dos professores acerca da Educação Estatística e a sua compreensão do potencial lúdico dessas.

\section{AS VIVÊNCIAS LÚDICAS NAS ATIVIDADES ESTATÍSTICAS}

Os professores foram questionados acerca das atividades estatísticas que eles desenvolviam, se essas poderiam proporcionar vivências lúdicas aos alunos. Emergiram desse questionamento respostas dos docentes apresentando os feedbacks, as reações, sentimentos e as emoções dos alunos frente às atividades propostas, estes são apresentados nos excertos abaixo,

P1: Ah sim, com certeza, eles chegam super empolgados. Querendo contar o que fizeram, ver o resultado [referindo-se a atividades de pesquisa].

P4: eu acho que sim, eles vem pra aula pensando "o que o professor preparou pra mim hoje", eles não querem sempre chegar "ah bota a data, bota o texto" eles querem chegar lá e ver hoje tem alguma coisa diferente [referindo-se a uma atividade com gráficos].

(Entrevista com os professores, 2017) 
Frente a estes discursos, foi realizado um questionamento mais direto, no qual a entrevistadora pergunta: "E como tu percebestes que eles gostaram?". As professoras responderam:

P4: eles se manifestam, eles vibram [...] na questão da salada de frutas teve muito isso, eles gostaram de fazer a atividade coletiva e depois comer as frutinhas que eles mesmos tinham levado [ao relatar uma atividade envolvendo a interpretação da frequência de certas frutas levadas pelos alunos para um piquenique].

P7: pelo prazer deles de fazer, tu não precisa pedir pra que a criança participe, ela já vem participando, pergunta "ah tia posso usar isso posso usar aquilo" eles já vão arredando a classe quando sabem que é gráfico, pegando o materialzinho já sabem que vão pegar tesoura, cola aquele negócio todo, entende.

(Entrevista com os professores, 2017)

Percebemos, nesse momento, mais uma vez a relação que os professores estabelecem entre a motivação, o interesse e a ludicidade. Essas crenças rompem a visão estática, stricto sensu do lúdico e abre um universo de possibilidades e de práticas potencialmente lúdicas no âmbito educacional.

Alguns professores relatam que não perceberam sentimentos e vivências lúdicas por parte de seus alunos ao realizarem pesquisas de campo, quando a atividade envolvia a pesquisa de preços em mercados do bairro, possivelmente porque não era uma atividade que englobasse a realidade deles. Entretanto, uma professora elucidou que em outra atividade de pesquisa, dessa vez envolvendo os familiares, a possibilidade dessa experiência ter proporcionado vivências lúdicas tenha aumentado porque "era uma realidade próxima deles, não tiveram que ir muito longe para conseguir, talvez." (P2).

Em contrapartida, a mesma professora relata que nem sempre a família tem interesse em participar das pesquisas realizadas por seus filhos, assim compreendemos que a recepção da família frente às atividades de pesquisa, muitas vezes, pode ser uma barreira entre o planejamento de uma atividade que visa a construção de conhecimento por meio da pesquisa e a sua execução. Desse modo, a resistência da família em se engajar nas atividades propostas pela escola pode influenciar negativamente em como a criança vai experenciar esta atividade. Por exemplo, uma atividade pode apresentar potencial lúdico (ser vivenciada pela criança de forma que the traga a sensação de bem- estar, prazer e alegria), porém, se a família negar-se a realizar a referida atividade, a criança pode vir modificar suas crenças em relação a mesma, passando a não mais concebê-la como lúdica.

Resultados similares foram encontrados por Blank e Silva (2017). Casarin e Ramos (2007), ao estudarem as relações entre a família e a aprendizagem, elucidam que tanto 0 desempenho escolar quanto a aprendizagem dependem, primeiramente, da inter-relação familiar e, ulteriormente, da relação professor-aluno e outros diversos fatores.

Diante desse cenário, uma possibilidade para a realização de pesquisas apresentar potencial lúdico é, de acordo com o professor 6 (que leciona no $5^{\circ}$ ano), realizar pesquisas com a população da escola. Contudo, vale relembrar, o que é vivenciado como lúdico por um aluno pode não o ser por outro. Essa concepção é identificada no trecho abaixo, recorte do discurso do professor 6 quando questionado se ele compreendeu a realização de pesquisas como lúdica pelos seus alunos,

P.6: eu tenho alunos que não gostam de jogar, eles não gostam de sair e se expor (nas pesquisas), isso é muito de cada um. Já eu tenho alunos que adoram, esse tipo de coisa, que vão lá pra frente, porque eles apresentam depois os resultados (da 
pesquisa) do que eles constroem, e uns adoram e outros ficam extremamente tímidos. Consigo ver em muitos que estão felizes e motivados e outros que não se motivam. [...] são uma minoria, geralmente eles gostam bastante de trabalhar com isso.

(Entrevista com os professores, 2017)

Conforme pode-se constatar, a realização de pesquisas é potencialmente lúdica para a maioria dos alunos do professor 6. Desse modo apresentamos a seguir a sistematização da atividade referido pelo professor. Todavia, não o fazemos com objetivo de apresentar uma "receita", mas, instigar 0 leitor a refletir sobre possibilidades para inserção da Estatística nos Anos Iniciais, de modo a tornar 0 aluno ativo no seu processo de ensino e aprendizagem, valorizando suas motivações, interesses e afetos, e desse modo, quem sabe, possibilitar vivências lúdicas aos seus alunos.

\title{
Quadro 1 - Sistematização de uma estratégia pedagógica de pesquisa (Professor 6)
}

\begin{abstract}
1) Divisão da turma em pequenos grupos: os alunos, de acordo com suas preferências, dividiram-se em pequenos grupos, de 4 ou 5 pessoas.

2) Debates entre os membros de cada grupo: os estudantes realizaram uma "chuva de ideias" e elencaram possibilidades de temas a serem investigados. Discutiram e escolheram um tema a ser pesquisado por cada grupo.

3) Escolha da população: os estudantes, sob orientação do professor, definiram que participariam da pesquisa as outras turmas dos Anos Iniciais da escola, do $1 .^{\circ}$ ao $4 .^{\circ}$ ano.

4) Criação de um instrumento de coleta de dados: nessa fase, os integrantes de cada grupo discutiram sobre quais seriam as questões a serem pesquisadas. Foram incluídas questões que resultaram na coleta de variáveis quantitativas, tais como: quantidade de horas que uma pessoa fica no celular; também questões que retornaram variáreis qualitativas, tais como: aparelho tecnológico você utiliza com maior frequência. Cada grupo criou questões. No final, todas as perguntas compuseram um questionário maior, do qual foram feitas cópias para serem entregues aos participantes da pesquisa. Aqui fica evidente a mediação do professor durante todo o processo.
\end{abstract}

5) Organização da turma em grupos para a coleta de dados: o questionário foi impresso e deveria ser de autopreenchimento. Cada grupo deveria entregar os questionários para serem respondidos por estudantes de cada ano da escola. No entanto, nas turmas de $1 . .^{\circ}$ e $2 .^{\circ}$ anos, nas quais os alunos ainda não são alfabetizados, os alunos pesquisadores coletaram os dados fazendo entrevistas individuais.

6) Coleta de dados: na coleta de dados, cada grupo ficou responsável por aplicar, em uma turma da escola, o questionário com as questões de todos os grupos.

7) Organização dos dados: os alunos pesquisadores, após a coleta de dados, destacaram dos questionários a questão que haviam criado para posterior análise. De posse das questões respondidas, cada grupo organizou em tabelas os dados coletados e criou um cartaz com um gráfico para sua representação, utilizando cartolina, papel a metro, canetinhas e outros materiais.

8) Interpretação dos resultados: cada grupo entre si discutiu os resultados obtidos, por meio predominantemente de gráficos e tabelas.

9) Conclusões e divulgação: cada grupo apresentou os resultados de sua pesquisa ao restante da turma, e foi aberto um momento de discussão da turma como um todo em relação aos resultados da pesquisa.

Fonte: Votto e Porciúncula (2019, p. 33-34)

A estratégia pedagógica descrita acima foi publicada pelas autoras deste artigo no livro "Perspectivas para 0 ensino e aprendizagem de Estatística e Probabilidade" (LOPES, PORICÚNCULA \& SAMÁ, 2019) intitulado "Estatística nos Anos Iniciais do Ensino Fundamental: estratégias pedagógicas" (VOTTO \& PORCIÚNCULA, 2019). Neste é realizada uma discussão acerca desta estratégia, entre outras, que versam sobre a coleta de informações na turma dos anos iniciais e construção coletiva de gráficos, uma dessas será também apresentada mais adiante. 
0 professor 6 enfatiza a importância do trabalho com pesquisa a partir de temas do interesse da turma, pois infere que cada turma tem curiosidades sobre fatos, objetos e situações distintas. Nesse sentido, elucida que os "temas pesquisados, [na turma B foram] tecnologias, celulares, computador ou videogames". Ao contrário dos temas que são atrativos para a outra turma na qual o professor leciona, ambas de $5^{\circ}$ ano, "na turma $A$ [os temas foram] quais as brincadeiras que eles gostavam de fazer, opções: queimada, pega-pega e esconde-esconde" (P6).

Face ao exposto no discurso do professor, percebemos que o trabalho com projetos de pesquisa não deve ocorrer de uma forma imposta de maneira vertical e autoritária, mas que deveria enaltecer os interesses da turma, esta é uma característica fundamental ao concebemos uma jornada para a educação potencialmente lúdica. Diversas pesquisas elucidam a importância da escolha do tema a ser pesquisado emergir da curiosidade, do contexto social no qual os alunos estão inseridos (FAGUNDES, SATO \& LAURINO-MAÇADA, 1999; OLIVEIRA, 2008).

Percebemos que a prática de pesquisa pode ser uma estratégia para possibilitar vivências lúdicas a alguns alunos, assim como outras quaisquer. Entretanto, diversos fatores podem ter contribuído para que esta prática não tenha sido vivenciada como lúdica por alguns estudantes.

Nesse contexto, salientamos que a pesquisa como princípio educativo, como elucidou Demo (2015), apresenta-se em diversos estudos por evidenciar o desenvolvimento do pensamento, da reflexão crítica, do fazer, do reconstruir constante, desenvolvendo, além de habilidades conceituais nos alunos, a sua autonomia e criticidade (FREIBERGER \& BERBEL, 2009; OLIVEIRA \& CAMPELLO, 2016; RAUSCH \& SCHROEDER, 2010). Além disso, a pesquisa escolar científica apresenta-se na BNCC (BRASIL, 2018) como uma habilidade a ser desenvolvida pelos alunos desde os primeiros anos da alfabetização.

No que tange à construção de gráficos e tabelas a partir de pesquisas ou levantamentos em sala de aula, percebemos que, de forma geral, tais atividades têm um potencial lúdico. Tendo em vista os enunciados abaixo,

P2: no gráfico aí sim, porque eles tinham bastante dificuldade, mas eles tinham motivação, notei que apesar da dificuldade eles tinham envolvimento [...] eles gostaram muito, [...] foi legal porque eles fizeram tudo, a construção, o desenho o recorte, tudo foi eles, eu trabalhei conteúdo e eles fizeram uma construção.

P3: quando a gente constrói um cartaz, todos participam, isso mobiliza, faz eles quererem, eles fazem parte desse processo, a gente constrói junto, não é algo que eu traga pronto [...] [uma atividade de gráfico com caixinhas de leite] ah eles gostam, porque tudo que traz movimento, que gere algo com o concreto, chama muito mais a atenção deles e envolvimento.

(Entrevista com os professores, 2017)

Embora a professora 2 tenha denotado que as atividades de pesquisa, no que tange à fase de coleta de dados, talvez não tenham proporcionado sentimentos lúdicos a todos os alunos, expõe que durante a análise dos dados e construção dos gráficos esse quadro se modificou. Podemos refletir sobre essa situação e nos indagarmos se as atividades que são desenvolvidas pelos alunos de forma coletiva tendem a proporcionar maiores possibilidades de vivências lúdicas, em detrimento de situações em que eles são colocados a realizar as tarefas sozinhos.

Considerando 0 exposto no trecho acima pela professora 3, no que concerne a reação dos alunos mediante uma atividade de construção de gráficos com material concreto, valendo-se de caixas 
de leite: "ah eles gostam, porque tudo que traz movimento, que gere algo com o concreto, chama muito mais a atenção deles e envolvimento", a seguir aprestamos a sistematização dessa atividade, que de acordo com a professora demonstrou potencial lúdico,

Quadro 2 - Sistematização de uma estratégia de coleta de informações e construção de um gráfico coletivamente (professora 3)

1) Tarefa para casa: cerca de três dias antes da construção do gráfico, foi solicitado aos alunos que levassem para a próxima
aula uma caixinha de leite vazia e higienizada.
2) Customização das caixinhas: no dia seguinte, os alunos realizaram a customização de suas caixinhas, com diferentes materiais
como têmpera, glitter, papel colorido, entre outros.
3) Preparação para a construção do gráfico: no dia da construção do gráfico coletivo, a professora colocou no chão cartões
com desenhos de algumas brincadeiras, como bola, bicicleta e videogame. Estas são variáveis qualitativas, que compuseram
as categorias do gráfico.
4) Construção do gráfico: com as crianças em círculo e os cartões expostos no chão numa linha imaginária (eixo X), e os alunos
colocaram a sua caixinha na frente do local onde se encontrava o cartão com a sua brincadeira favorita. Assim, os alunos empilha-
ram as caixinhas conforme seus interesses e construíram um gráfico com material concreto,
Fonte: Votto e Porciúncula (2019, p. 27)

Indo ao encontro do exposto pela professora 3 , a professora 7 ressalta que 0 trabalho com construção, adotando metodologias mais ativas (MAURl, 2006) tornou o seu trabalho mais eficaz, em suas palavras,

P7: Realmente eu notei que o prazer deles em estar ali foi muito gratificante, tanto é que de 20 alunos 16 passaram lendo, tu vais mudando a maneira de trabalha a cada ano, esse ano trabalhar mais com criação, construção proporcionou uma aprendizagem bem maior.

(Entrevista com os professores, 2017)

A partir desses excertos percebemos que as atividades em que há interação entre os alunos, como a pesquisa no ambiente da turma ou da escola, ou ainda a organização de dados coletados em pesquisa fora desse ambiente de forma individual e analisados coletivamente, podem proporcionar aos alunos um envolvimento e motivação. Assim, ressaltamos que o motor do processo de aprendizagem é o sentido atribuído pelo aluno ao que está sendo estudado, nesse processo estão implicados os aspectos motivacionais e afetivo-relacionais (SOLÉ \& COLL, 2006). Quando consideramos esses aspectos estamos contribuindo para uma educação potencialmente lúdica.

É imprescindível salientar que quando falamos em metodologias ativas, em proporcionar ao estudante ser ativo no seu processo de aprendizagem, não significa que seja necessário apenas colocar o corpo em movimento, agindo sobre algo. Mas sim, que aluno, o sujeito, tenha uma ativa elaboração mental sobre 0 que se está fazendo, sobre os seus porquês, refletindo e indagando frequentemente sobre as ações que desempenha (MAURI, 2006). Esses pressupostos vão ao encontro do que Demo (2015) denomina de questionamento reconstrutivo. Este não seria a crítica pela crítica, mas a possibilidade do aluno pensar, refletir e planejar um projeto de vida, do qual valha-se do seu conhecimento, construído e (re)construído por meio da pesquisa como princípio educativo, vivenciada diariamente na sala de aula. Nesta, o professor pode valer-se dos interesses e motivações lúdicas dos estudantes. 
Acentuamos ainda um exemplo de atividade que versa sobre construção de tabelas pronunciado pela professora 3 ,

P3: Eles tinham também um calendário individual, em que foram anotando e desenhando o clima de cada dia, um sol, nuvens ou chuva, e uma vez por mês se criava uma tabela coletiva questionando os alunos, quantos dias fez sol, quantos dias choveu esse mês. Nesse calendário eles também anotavam as faltas, e também era problematizado e incentivado quem faltou menos a aula etc. E isso é bem motivador, eles não querem faltar, porque eles querem ter zero na coluna das faltas.

(Entrevista com os professores, 2017)

A partir desse excerto e de outros expostos ao longo dessa análise, percebemos 0 quanto a motivação é um fator que está atrelado à prática pedagógica e, por conseguinte, imbricado na percepção acerca da ludicidade dos docentes. Concebemos, apoiados em Tapia e Fita (2006, p. 77), que a motivação pode ser compreendida em diferentes níveis, a saber: motivação intrínseca; motivação relacionada com o eu; motivação centrada na valorização social e motivação relacionada a recompensas externas. No âmbito escolar, a motivação é um determinante crítico do nível e da qualidade da aprendizagem e do desempenho (GUIMARÃES \& BORUCHOVITCH, 2004; REQUIA, 2015).

Nessa direção, algumas pesquisas têm evidenciado que ao longo do processo de escolarização, a motivação intrínseca tende a sofrer um declínio. Ou seja, os estudantes ao final dos anos iniciais, não apresentam a mesma curiosidade, motivação e gosto pelo desafio, pelas descobertas observadas nos primeiros anos da infância (LEPPER, CORPUS \& IYENGAR, 2005; PAIVA \& BORUCHOVITCH, 2010). Tais dados corroboram os resultados do presente artigo, quando algumas professoras, a exemplo de P2, relatam essa perda de interesse pelo ambiente escolar, observado no trecho a seguir, "no $1^{\circ}$ ano é diferente, é curiosidade, descobertas, eles têm muito interesse, é tudo muito novo, um show. No $5^{\circ}$ ano é 'lá vem ela de novo' [...] no $1^{\circ}$ ano tudo flui." (P2).

A situação posta acima nos faz refletir sobre o porquê ocorre esse declínio da motivação dos alunos ao longo de sua trajetória escolar. Podemos pensar em inúmeras respostas e suposiçôes a esses questionamentos, dentre eles o programa de conteúdos que se intensifica durante a escolarização do aluno, as concepções dos professores acerca do processo pedagógico, do currículo e da ludicidade - essa por vezes pautada apenas na sua materialidade e no seu sentido stricto sensu. Nesse sentido, destacamos que o professor, ao assumir uma atitude lúdica, pode vir a proporcionar aos seus estudantes, vivências também lúdicas. Fato este que poderia contribuir para a (re)construção dessa motivação e interesse do aluno frente ao âmbito educacional, atrelada à construção de conhecimentos.

Nesse contexto, recorremos aos escritos de Gal, Ginsburg e Schau (1997), ao enfatizarem que 0 papel das atitudes e crenças na Educação Estatística podem refletir na resolução de problemas, aludindo que os alunos precisam se sentir seguros e à vontade no processo de construção do conhecimento.

Levando em consideração tais aspectos afetivos, as crenças e atitudes discentes, acreditamos que 0 educador que tem uma atitude lúdica na sua prática pedagógica, pode proporcionar aos estudantes vivências lúdicas, valorizando as motivações lúdicas destes. Tal crença pode ser exemplificada no trecho,

P7: Na verdade pensando nesse conceito que tu trouxe, a gente acaba tornando, proporcionando o lúdico pra eles nas atividades diárias, as vezes não precisa nem ser uma atividade totalmente planejada, as vezes a maneira como tu fala como tu 
constrói e vendo o prazer deles [...] eu percebi que trabalhei muita coisa lúdica sem saber que era lúdico.

(Entrevista com os professores, 2017)

Face o excerto acima, percebemos que é possível cotidianizar a ludicidade, tornando-a uma atitude docente diária. De acordo com a professora 7, esta dispunha de uma atitude lúdica na sua prática pedagógica, mesmo que de forma inconsciente. Nesse sentido, compreendemos que trazer à consciência essa prática pode potencializar tal atitude docente. Este fato reitera a relevância de cursos de formação continuada, nos quais os professores são capazes de refletir sobre a sua prática e compreender o que, de fato, estão realizando e as crenças que subjazem a sua prática, tanto lúdica quando estatística.

No que tange à formação profissional, a relevância da ludicidade passa a ser percebida, inclusive, como um dos saberes necessários aos docentes, juntamente aos saberes profissionais, disciplinares, curriculares e experienciais preconizados por Tardif (2002), uma vez que a falta de interesse pelo estudo e pela qualificação é o primeiro motivo da evasão escolar entre jovens de 15 a 29 anos, que não têm instrução ou que não completaram o Ensino Fundamental (IBGE, 2019).

Face ao exposto, o professor do século XXI não pode mais ficar alheio às motivações e interesses dos alunos, visto que essas podem contribuir para os altos índices de evasão escolar. Assim, conceber a ludicidade como um saber indispensável aos docentes, pode contribuir no desenvolvimento de profissionais pesquisadores e reflexivos, comprometidos com a subjetividade discente. Desse modo, tende a minimizar a distância entre o professor e 0 sistema educativo dos interesses dos alunos, como aponta Demo (2007, p. 15) "as expectativas dos alunos [...] são referências inarredáveis de uma boa escola".

Por fim, é importante frisar que as atividades que proporcionam vivências lúdicas aos sujeitos passam a ser vistas como indispensáveis à vida humana e não algo limitado ao universo infantil. Em relação à Educação Estatística, a partir dos discursos dos professores investigados, percebemos que, apesar de algumas situações envolvendo a coleta de informações fora do ambiente escolar não terem proporcionado vivências lúdicas aos alunos, de modo geral as atividades que envolvem a construção de gráficos e tabelas de forma dinâmica e coletiva, além da realização de pesquisas no âmbito da escola possuem um grande potencial lúdico.

Tais atividades podem contribuir para a motivação e o interesse dos alunos por atividades realizadas no âmbito escolar, essa é uma preocupação dos profissionais que estudam a Educação Estatística, posto que esta investiga tanto aspectos cognitivos quanto afetivos do processo educativo de ensinar e aprender Estatística (GAL, GINSBURG \& SCHAU, 1997; CAZORLA et. al., 2017).

\section{CONSIDERAÇÕES FINAIS}

0 presente artigo analisou, num primeiro momento, como os professores investigados concebem a ludicidade, e na sequência, buscou identificar o potencial lúdico das estratégias pedagógicas realizadas por estes professores para o ensino e aprendizagem de Estatística nos Anos Iniciais do Ensino Fundamental. A partir das análises do corpus que compõe esta pesquisa, emergiram duas subcategorias temáticas: As compreensões de professores dos Anos Iniciais acerca da ludicidade e Vivências lúdicas nas atividades estatísticas.

No que se refere à subcategoria As compreensões de professores dos Anos Iniciais acerca da ludicidade, emergiram dos resultados compreensões docentes a partir de um sentido stricto sensu 
do lúdico. Ou seja, por meio da crença de certa materialidade da ludicidade, ao relacioná-la principalmente aos jogos e brincadeiras. Nessa direção, foi atrelado ao lúdico, ainda, algumas funções como: romper com formas tradicionais de ensino; introdução aos conteúdos; função lúdica x função pedagógica e facilitar a aprendizagem ao aprender brincando.

Contudo, o discurso de uma professora investigada engloba uma visão latu sensu do lúdico, ao concebê-lo não apenas a partir da sua materialidade em jogos e brincadeiras, mas a partir de uma atitude docente, considerando a subjetividade de seus alunos. Conceituamos neste artigo, a partir dos discursos docentes e dos referenciais teóricos adotados, que a atitude lúdica docente se refere à forma com que o professor se coloca diante da turma, a sua capacidade de planejar e conduzir as atividades considerando a subjetividade discente, envolvendo no contexto educativo os afetos, motivações e interesses dos alunos, colaborando para vivências lúdicas ${ }^{4}$ destes.

A categoria Vivências lúdicas nas atividades estatísticas descortinou o potencial lúdico presente nas atividades que tornam 0 aluno ativo em seu processo de aprendizagem. Estas ocorrem geralmente por meio de atividades coletivas, de pesquisa e construção de gráficos, envolvendo tanto 0 apoio de materiais concretos, quanto uma atitude lúdica docente.

Compreendemos que as atividades que proporcionam vivências lúdicas passam a ser vistas como indispensáveis à vida humana e não algo restrito ao universo infantil. Por conseguinte, é possível experenciar de forma lúdica diversas ações e atividades, incluindo as realizadas no âmbito escolar para 0 ensino e aprendizagem estatística. Assim, salientamos que o professor que almeja uma educação lúdica, deve dotar-se de uma atitude também lúdica. Esta, por vezes, pode ser inconsciente, 0 que evidencia a importância da formação continuada de professores, visando trazer à consciência essa prática. Desse modo, torna-se possível cotidianizar a ludicidade, tornando-a uma atitude docente diária que poderá repercutir em vivências lúdicas aos educandos.

\section{REFERÊNCIAS}

ALMEIDA, P. N. Educação Lúdica: técnicas e jogos pedagógicos. São Paulo: Loyola, 1987.

ARAÚJO, I. R. 0. A utilização de lúdicos para auxiliar a aprendizagem e desmistificar o ensino da matemática. 2000. 137 f. Dissertação (Mestrado em Engenharia de Produção) - Universidade Federal de Santa Catarina, Florianópolis, 2000.

BARDIN, L. Análise de conteúdo. Lisboa: Edições 70, 2011.

BATANERO, C. Didáctica de la Estadística. Departamento de Didáctica de la Matemática, Universidad de Granada. 2001. 219 p.

BLANK, C. K; SILVA, J. A. Professores como pesquisadores e a colaboração entre pares: pesquisa, informação e conhecimento no contexto escolar. ETD - Educação Temática Digital, Campinas, v. 19, n. 3, p. 786-804, jul./set. 2017.

BORBA, R. et al. Educação Estatística no ensino básico: Currículo, Pesquisa e Prática em sala de aula. EM TEIA Revista de Educação Matemática e Tecnológica Ibero-Americana, v. 2, n. 2, p. 1-18, 2011.

40 conceito de lúdico, adotado neste artigo, refere-se à subjetividade do sujeito, separando-se do objeto (CHATEAU, 1987), ou seja, é tomado como um fenômeno interno que tem manifestações no exterior (BROUGËRE 1998; LUCKESI, 2002). 
BRASIL. Parâmetros Curriculares Nacionais: Matemática. / Ministério da Educação. Secretaria de Educação Fundamental. Brasília, 1997. 142p.

. Pacto Nacional pela Alfabetização na Idade Certa: Educação Estatística. / Ministério da Educação. Secretaria de Educação Básica. Diretoria de Apoio à Gestão Educacional. Brasília, 2014.

Base Nacional Comum Curricular: Educação é a Base. / Ministério da Educação. Brasília, 2018. Disponível em: https://bit.ly/37qTblC.

BROUGÈRE, G. Jogo e educação. Porto Alegre: Artes Médicas, 1998.

Brinquedo e cultura. São Paulo: Cortez, 2006.

CASARIN, N. E. F.; RAMOS, M. B. J. Família e aprendizagem escolar. Rev. psicopedag., São Paulo, v. 24, n. 74, p. 182-201, 2007.

CAZORLA, I. et al. Estatística para os Anos Iniciais do Ensino Fundamental. [livro eletrônico]. 1. ed. Brasília: SBEM, 2017.

CHATEAU, J. 0 Jogo e a Criança. São Paulo: Summus. [1954]. 1987.

DANTAS, H. Brincar e Trabalhar. In: KISHIMOTO, T. M. (Org.). 0 brincar e suas teorias. São Paulo: Pioneira Thomson Learning, 2002. p. 111-122.

DEMO, P. 0 porvir: desafio das linguagens do século XXI. Curitiba: Ibpex, 2007.

Educar pela Pesquisa. Campinas: Autores Associados, 2015.

FAGUNDES, L. da; SATO, L.; LAURINO-MAÇADA, D. L. Aprendizes do futuro: as inovações começaram! MEC, Coleção Informática para a Mudança na Educação, 1999. Disponível em: http://mathematikos.mat.ufrgs.br/.

FRANKLIN, C. et al. Guidelines for Assessment and Instruction in Statistics Education (GAISE) Report: a Pre-K-12 curriculum framework. Alexandria/VA: ASA, 2007.

FREIBERGER, R. M.; BERBEL, N. A. N. A importância da pesquisa como princípio educativo na atuação pedagógica de professores de educação infantil e ensino fundamental. In: IX CONGRESSO NACIONAL DE EDUCAÇÃO - EDUCERE, III ENCONTRO SUL BRASILEIRO DE PSICOPEDAGOGIA, Paraná. Anais... Paraná, 2009. p. 7889-7902.

FREIRE, P. Ação Cultural para a liberdade. Rio de Janeiro: Paz e Terra, 1981.

Pedagogia da Autonomia: saberes necessários à prática educativa. São Paulo: Paz e Terra, 2002.

GAL, I. Adults Statistical Literacy: meanings, components, responsibilities. International Statistical Review, v. 70, n. 1, p. 1-25, 2002.

; GINSBURG, L.; SCHAU, C. Monitoring Attitudes and Beliefs in Statistics Education. In: GAL, I.; GARFIELD, J. B. (Eds.). The Assessment Challenge in Statistics Education. Voorburg, Netherlands: IOS Press, 1997. p. 37-51. Disponível em: https://bit.ly/2IPReVu. 
GUIMARÃES, G. et al. Educação estatística na educação infantil e nos anos iniciais. Zetetiké Cempem - FE Unicamp, v. 17, n. 2, p. 11-28, jul./dez. 2009.

GUIMARÃES, S. E. R.; BORUCHOVITCH, E. 0 estilo motivacional do professor e a motivação intrínseca dos estudantes: uma perspectiva da teoria da autodeterminação. Psicologia: Reflexão e Crítica, v. 17, n. 2, p. 143-150, 2004.

HUIZINGA, J. Homo Ludens - 1938. São Paulo: Perspectiva, 1971.

IBGE. Educação 2018. Pesquisa Nacional por Amostra de Domicílios Contínua - PNAD, 2019. Disponível em: https:// bit.ly/34gcxHT.

KISHIMOTO, T. M. 0 jogo e a Educação Infantil. São Paulo: Pioneira, 1998.

(Org.). Jogo, brinquedo, brincadeira e a educação. São Paulo: Cortez, 2006.

LAPA, L. D. P. A ludicidade como ferramenta no processo de ensino-aprendizagem da matemática: passeando por Brasília e aprendendo geometria: experiências numa escola da periferia do Distrito Federal. 2017. xii, 96 f. Dissertação (Mestrado Profissional em Matemática) - Universidade de Brasília, Brasília, 2017.

LEPPER, M. R.; CORPUS, J. H.; IYENGAR, S. S. Intrinsic an extrinsic motivational orientation in the classroom: age differences and academics correlates. Journal of Educational Psychology, v. 97, n. 2, p. 184-196, 2005.

LIBÂNEO, J. C. Democratização da escola pública: A pedagogia Crítico Social dos Conteúdos. São Paulo: Loyola, 1985.

LUCKESI, C. C. Filosofia da Educação. - São Paulo: Cortez, 1994.

Desenvolvimento dos estados de consciência e ludicidade. Cadernos de Pesquisa do Núcleo de FACED/ UFBA, v. 2, n. 21, p. 9-25, 1998.

Educação, ludicidade e prevenção das neuroses futuras: uma proposta pedagógica a partir da Biossíntese. Educação e Ludicidade, Coletânea Ludopedagogia, FACED/UFBA, 2000.

. Ludicidade e atividades lúdicas: uma abordagem a partir da experiência interna. In: PORTO, B. de S. (Org.). Ludicidade: 0 que é mesmo isso? Salvador: Universidade Federal da Bahia, Faculdade de Educação, Programa de Pós-Graduação em Educação, Gepel, 2002.

Brincar III: a criança e sua poética. (Material obtido através do website de Cipriano Carlos Luckesi), 2005. 4p.

LUGLE, A. M. C. Vivências lúdicas nas aulas de matemática: uma proposta pedagógica desenvolvida com alunos do ensino fundamental II ( $5^{\mathrm{a}}$ e $6^{\mathrm{a}}$ séries) em uma escola particular de Londrina. 2006. 140 f. Dissertação (Mestrado em Educação) - Universidade Estadual de Londrina, Londrina, 2006.

MASCARIN, L. A. A utilização de atividades lúdicas e exploratórias no ensino e aprendizagem de matemática. 2017. 77 f. Dissertação (Mestrado Profissional em Matemática em Rede Nacional) - Universidade de São Paulo - USP, São Carlos, 2017. 
MAURI, T. 0 que faz com que 0 aluno e a aluna aprendam os conteúdos escolares: In: COLL, C. et al. 0 construtivismo na sala de aula. São Paulo: Ática, 2006.

MINAYO, M. C. de S. 0 desafio do conhecimento: pesquisas qualitativas em saúde. São Paulo: Hucitec, 2008.

OLIVEIRA, C. A. A pesquisa escolar em tempos de internet: reflexões sobre essa prática pedagógica. 2008. 145 f. Dissertação (Mestrado em Educação) - Universidade Federal do Paraná, Curitiba, 2008.

OLIVEIRA, I. R. de; CAMPELLO, B. S. Estado da arte sobre pesquisa escolar no Brasil. Transinformação, Campinas, v. 28, n. 2, p. 181-194, ago. 2016.

PAIVA, M. L. M. F.; BORUCHOVITCH, E. Orientações motivacionais, crenças educacionais e desempenho escolar de estudantes do ensino fundamental. Psicologia em Estudo, v. 15, n. 2, p. 381-389, 2010.

PERRENOUD, P. A prática reflexiva no ofício do professor: Profissionalização e Razão Pedagógica. Porto Alegre: Artmed, 2002.

PIN, V. P. G. Jogos de reflexão pura como ferramenta lúdica para a aprendizagem matemática. 2016. 134 f. Dissertação (Mestrado em Educação) - Universidade de Brasília, Brasília, 2016.

RAUSCH, R. B.; SCHROEDER, S. L. A inserção da pesquisa nas séries iniciais do ensino fundamental. Atos de pesquisa em educação - PPGE/ME FURB, v. 5, n. 3, p. 315-337, set./dez. 2010.

REQUIA, R. A relação entre a motivação e desempenho escolar em alunos dos anos iniciais do ensino fundamental: um estudo na escola Municipal de Ensino Fundamental Padre Gabriel Bolzan. 2015. 76 f. Dissertação (Mestrado Profissional em Gestão de Organizações Públicas) - Universidade Federal de Santa Maria, Santa Maria, 2015.

SARTORI, A. S. T. 0 lúdico na educação matemática escolar: efeitos na constituição do sujeito infantil contemporâneo. 2015. 158 f. Dissertação (Mestrado em Educação Científica e Tecnológica) - Universidade Federal de Santa Catarina, Florianópolis, 2015.

; DUARTE, C. G. 0 Sujeito Lúdico Produzido pela/na Educação Matemática: Interlocuções com o neoliberalismo. Bolema, Rio Claro, v. 31, n. 57, p. 53-69, 2017.

SOLÉ, I.; COLL, C. Os professores e a concepção construtivista. In: COLL, C. et al. 0 construtivismo na sala de aula. São Paulo: Ática, 2006.

TAPIA, J. A.; FITA, E. C. A motivação em sala de aula. 7a. ed. São Paulo: Edições Loyola, 2006.

TARDIF, M. Saberes docentes e formação profissional. Petrópolis: Vozes, 2002.

VALIO, Denise T. Frações: estratégias lúdicas no ensino da matemática. 2014. 103 f. Dissertação (Mestrado em Ciências Exatas e da Terra) - Universidade Federal de São Carlos, São Carlos, 2014. 
VOTTO, T. R. As potencialidades lúdicas nas estratégias para 0 ensino e a aprendizagem estatística nos anos iniciais do ensino fundamental. 2018. Dissertação (Mestrado em Educação em Ciências: Química da Vida e Saúde) Universidade Federal do Rio Grande, Rio Grande, 2018.

VOTTO, T. R; PORCIÚNCULA, M. Estatística nos Anos Iniciais do Ensino Fundamental: estratégias pedagógicas. In: LOPES, C. E.; PORICÚNCULA, M.; SAMÁ, S. (Orgs.). Perspectivas para o ensino e aprendizagem de Estatística e Probabilidade. Campinas: Mercado Letras, 2019.

VOTTO, T. R.; SCHREIBER, K.; PORCIÚNCULA, M. "Educação estatística nos anos iniciais do ensino fundamental". Cad. Pesq., v. 24, n. esp., São Luís, p. 143-158, 2017.

RECEBIDO EM: 24 jun. 2020

CONCLUÍDO EM: 24 set. 2020 